\title{
Decolonizing Technology and Society: A Perspective from the Global South
}

\author{
Anna Bon, Francis Dittoh, Gossa Lô, Mónica Pini, Robert Bwana, \\ Cheah WaiShiang, Narayanan Kulathuramaiyer, and André Baart
}

\begin{abstract}
Despite the large impact of digital technology on the lives and future of all people on the planet, many people, especially from the Global South, are not included in the debates about the future of the digital society. This inequality is a systemic problem which has roots in the real world. We refer to this problem as "digital coloniality." We argue that to achieve a more equitable and inclusive global digital society, active involvement of stakeholders from poor regions of the world as co-researchers, co-creators, and co-designers of technology is required. We briefly discuss a few collaborative, community-oriented technology development projects as examples of transdisciplinary knowledge production and action research for a more inclusive digital society.
\end{abstract}

\author{
A. Bon $(\bowtie)$ \\ w4ra.org, Vrije Universiteit Amsterdam, Amsterdam, The Netherlands \\ e-mail: a.bon@vu.nl \\ F. Dittoh \\ University for Development Studies UDS, Tamale, Ghana \\ e-mail: fdittoh@uds.edu.gh \\ G. Lô · A. Baart \\ Bolesian BV, Utrecht, The Netherlands \\ e-mail: gossalo@bolesian.ai; andre@andrebaart.nl \\ M. Pini \\ Universidad San Martín, Buenos Aires, Argentina \\ e-mail: mpini@unsam.edu.ar \\ R. Bwana \\ University of Amsterdam, Amsterdam, The Netherlands \\ e-mail: r.m.bwana@uva.nl \\ C. WaiShiang $\cdot$ N. Kulathuramaiyer \\ University Malaysia, Sarawak, Malaysia \\ e-mail: wscheah@unimas.my; nara@unimas.my




\section{Inclusion, Coloniality, and the Digital Society}

People from poor environments, e.g., in the Global South, are not often included in debates about the digital society. This is surprising, as impacts from digital technologies do have far-reaching consequences for their lives and future. Nowadays, the rapid co-evolution of society and technology is calling for reflection, deliberation, and responsible action. Scientists are posing the question: "Are we humans defining technology or is technology defining us?" (Lee 2020), but who are "we" in this question? Who is defining technology, and who has the knowledge, the assets, and the decision-making power?

A way to understand the impacts of digital transformation for people in the Global South is to observe the digital society through a decolonial lens. This helps to understand the, often tacit, patterns of power in the social and technological fabric. If we consider the digital society to be an image of the physical world, it will have inherited, along with other aspects, historical patterns of inequality. These patterns are referred to as "coloniality" (Mendoza 2021, pp. 46-54; Mignolo and Walsh 2018, pp. 1-12; Quijano 2016, pp. 15-18).

At the moment of writing, about three billion people in the world are unconnected from the digital society - a phenomenon often called the digital divide - but this number is rapidly decreasing. Being connected, particularly through the Internet and Web, is generally seen as the key to a better life. With the breathtaking pace in which the Internet is rolled out even in remote corners of the world, universal connectivity, with full endorsement of the United Nations, ${ }^{1}$ might well soon be completed. The follow-on question is: will omnipresent connectivity bring social justice, equality, and a more sustainable and prosperous world closer to all?

The World Wide Web, the backbone of the digital society, was designed, according to its inventor Tim Berners-Lee, as "an open platform that would allow everyone, everywhere to share information, access opportunities and collaborate across geographic and cultural boundaries" (Berners-Lee 2017). However, despite being a global common, the Web's wide penetration also makes it into a dominant standard. Through its ubiquity, the Web exerts pressure toward uptake, even if this uptake may harm the individual user. The alternative - refusing to be part of it results in isolation. This phenomenon, which is described by David Grewal as network power, is common for networked standards (Grewal 2008, pp. 20-28). It makes the digital society into a hegemonic system from which - especially from the perspective of the Global South - there is no escape, despite the price users, communities, and even countries have to pay with their money or data, to become part of it.

When we observe the current structure of the digital society, we see that it is physically, economically, and socially extremely centralized and concentrated in the Global North, where to date the forbearers of many digital innovations reside. For

\footnotetext{
${ }^{1}$ See, e.g., https://www.un.org/development/desa/en/news/administration/internet-governance-2. html (Accessed 1 May 2021)
} 
example, the "cloud" is concentrated in large datacenters in wealthy countries. The commercialization of ICTs, influenced by the said centralization, further puts a large chunk of any wealth gathered by innovations in the Global South into the accounts of Big Tech (Zuboff 2019, pp. 63-96). The unequal competition in terms of storage, connectivity, funding, and adoption hampers startup-driven innovation in the Global South.

While digital technologies such as mobile phones are becoming cheaper and more widespread in all corners of the world, control over what can be installed sits in the hands of prominent private tech firms. Governance and decision-making of technology are in the hands of the private tech firms and still, at best, bound by norms and regulations set in countries of the Global North. And these are just a few examples of technological coloniality.

Technological coloniality can be observed in many sectors of society. In Argentina, for example, a country that lacks technological autonomy, the digital market is dominated by transnational corporate tech firms. These parties are taking over roles and functions from the State, for example, in education. They are providing through philanthropic gifts in the frame of so-called corporate social responsibility digital services to higher education institutes in exchange for market penetration, tax savings, branding, and policy influencing. The commercial activities of the Big Tech companies are targeting youngsters in particular with media, music, video, entertainment, and fake news. This further leverages trends of privatization (Pini 2020, pp. 37-40).

With new forms of digital communication and online education, intensified in 2020 during the COVID-19 pandemic, there is growing evidence of algorithms being used for surveillance of access, production, and circulation of information, goods, and services in society. These scenarios are seen in many countries, Argentina included. "Free" Internet, provided in exchange for user data, is the business model in which personal data are exploited as raw material (Zuboff 2019, pp. 70-73). Data, knowledge, expertise, and high-performance infrastructures are kept and mined by an increasingly smaller number of transnational corporations, using highly advanced digital technologies for value extraction and profit. While interventions "free of costs" and "free Internet connectivity" are justified as societal benefits, the influence of the private tech sector in vital sectors of society reveals the corporate coloniality.

Coloniality can be observed in many instances of technology. For example, in Artificial Intelligence (AI) algorithms, which previously were held to be objective and value-free, discriminating biases have been discovered (Mohamed et al. 2020, pp. 659-663). There are various examples of discriminating AI, as a result of biases that are hidden in the underlying data: e.g. an algorithm that autonomously whitens black and Asian faces; an application, based on a face recognition algorithm, that opens the door of an office for white faces only, but fails to recognize black 
faces. ${ }^{2}$ These trivial examples show biases embedded in apparently value-free technology, in which existing patterns are unconsciously replicated. These biases pop up unexpectedly in autonomous smart systems and may intentionally or unintentionally exacerbate inequalities. Artificial Intelligence is a technological domain that urgently needs to be innovatively decolonized.

\section{Community-Oriented, Transdisciplinary Models and Inclusive Platforms as Alternative}

At the brink of new technological breakthroughs, many scientists, aware of their responsibility, propose to bring together the brightest minds from various sectors and disciplines to discuss directions and propose solutions for the digital society (e.g., Berners-Lee 2019). The authors of this paper stress the importance to include, in these important platforms, also people from poor regions, e.g., in the Global South, and make their voices heard and their perspectives visible. To do so, we propose community-oriented research and collaborative technology development. While this can offshoot innovation in low-resource environments in unexpected ways, it can also be a source of inspiration for new forms of transdisciplinary knowledge production. We discuss a few examples.

In low-resource environments in Africa, many people do not have access to information which is relevant for their daily work. For example, smallholder farmers need local weather forecasts and data on actual rainfall and information on prices at local markets, on treatment of animal health, on the water quality in local wells, etc. However, information access is hampered not only due to a lack of Internet access: also cultural and social factors exist, for example, low literacy or language. These access barriers exist for the majority of rural communities in the Northern Region of Ghana.

In response to local needs, an exploratory design-science action-research project, dubbed Tibansim, was carried out in Northern Ghana, to develop new modes of digital access and information sharing for rural communities. Tibansim was deployed in five communities from the East Gonja District of the Savannah Region of Ghana. These are typically small communities with about 20 to 30 households. In this project, the Tibansim information system was developed, built on local initiatives and adapted to the local conditions. Tibansim provides farming-related information that is being collected, (re-)produced, and entered into the system by the community members themselves, so that it can be shared locally. It uses only technologies that are locally available: voice-based (GSM) mobile telephony and local community radio. The information is delivered to the users in their own local language(s) (Dittoh et al. 2021, pp. 1-23). Here, we see that it is not just about

\footnotetext{
${ }^{2}$ https://www.oneworld.nl/lezen/discriminatie/racisme/zwart-dan-rijdt-de-zelfrijdende-auto-joueerder-aan/ (Accessed: 1 May 2021)
} 
connectivity or platform access as such: the collaborative work on relevant and adequate information content is at least as important.

Similar initiatives have been carried out in Mali in the period 2011-2021. At the request of the national Malian smallholder farmer organization $\mathrm{AOPP},{ }^{3}$ a digital platform was developed to support their members - smallholder cereal seeds producers - in the seed trade. As soon as the first version of the Web-based seed trade platform was evaluated, it became clear that local requirements and contextual barriers had been overlooked by the technical developers (Vos et al. 2020, pp. 13-14). The system had to be adapted and re-designed in closer dialogue with its users. This second iteration resulted in a mobile, voice interface, spoken in the local language Bambara, as to be useful for farmers without literacy skills. This resulted in a complex set of requirements, as the platform should meet the requirements of the legacy non-digital local seed trade, the language and speech requirements, as well as the technical challenges to make it work in the absence of ubiquitous Internet connectivity.

In Sarawak, Malaysia, researchers and indigenous communities have worked together for over a decade, in search of sociotechnical solutions for local problems. One of the initiatives is eBario, ${ }^{4}$ a project that aimed at connecting the unconnected remote village of Bario to the digital society. The initiative consisted of a transdisciplinary university-community partnership between one of Borneo ethnic minorities, the Kelabit community, and the Institute of Social Informatics and Technological Innovations of the University Malaysia Sarawak. The project brought many unexpected spin-offs for the indigenous community, who took joint knowledge creation as a new pathway. The joint efforts transformed the project into a living lab for innovations in healthcare, local cultural preservation, and agriculture. The eBario model has been replicated in six sites: Long Lamai and Ba'Kelalan sites in Sarawak, Pos Lenjang and Pos Sinderut sites in Pahang, and Pos Gob and Pos Bala sites in Kelantan. Among its achievements is the development of communityled, lifelong learning initiatives. Improved skills, incomes, and social communications were outcomes of the eBario project for participating communities. At a national level, the project has influenced policy-making for rural development. For academics, it brought new insights how to do ICT4D research that also seeks to improve the lives of marginalized and underserved communities (Harris et al. 2018, pp. 63-68). Projects such as these show that it is not just about universal connectivity per se: significant effort has to be spent on collaboratively shaping the societal impacts of connectivity as the key to reaping benefits of digitalization.

What we learn from the above initiatives in low-resource environments is that whereas mainstream computer science and Artificial Intelligence are only focusing on high-performance systems, high-end computing, networking, and big data, it is also scientifically challenging and societally relevant to investigate how to design

\footnotetext{
${ }^{3}$ https://aopp-mali.com/ (Accessed 1 May 2021)

${ }^{4}$ https://www.itu.int/osg/spuold/wsis-themes/ict_stories/themes/case_studies/e-bario.html (Accessed 1 May 2021)
} 
small-scale solutions, decentralized systems, and green, energy-efficient technologies. For example, recent studies on small, inexpensive devices as the so-called "Kasadaka" platform ${ }^{5}$ have demonstrated the potential of decentralized, inexpensive platforms, hosted locally on small hardware as inclusive platforms for local communities in Mali, Burkina Faso, and Ghana (Baart et al. 2019, pp. 202-219).

Another important point in this research is that of contextualization. For example, deployment of Artificial Intelligence generally requires high- performance infrastructures. Artificial Intelligence's most popular branch, Machine Learning, uses heavy computing and needs sustainable data storage to process and store large amounts of data. Such infrastructure is not available in many countries of the Global South. Another issue is related to user data which raises privacy and security issues and requires regulatory frameworks that unfortunately are still in their infancy in many African countries. Still, there are alternative forms of AI, e.g., knowledgebased reasoning systems, that will work better under low-resource circumstances and can run on decentralized local systems. Examples include knowledge engineering for indigenous knowledge, co-designed by local farmers and AI specialists, or expert systems of traditional African medicine co-developed by local and AI experts (Lô et al. 2017). These topics are currently being studied in field-based pilot research projects.

The above examples are real-world research projects with a modest reach. Despite their small size, these projects show the importance of transdisciplinarity, involving local communities, not as passive subjects, but as co-researchers and co-creators. This model is also applicable in academic education. Currently, mainstream curricula in Computer Science and Artificial Intelligence introduce students only to high-end domains of technological innovation. Not many educational programs are devoted to community-centered technology development in resourceconstrained environments. Yet, the challenges of the global digital society are calling also for ICT professionals with the knowledge, skills, and responsibility to deal with these challenges. Collaborative technology development, reflection, and joint deliberation with respect for local agency and innovation can open new avenues toward responsible and societally oriented knowledge production and ethical technology development, striving for more equality and less coloniality in the (digital) society.

\section{Conclusion}

From the above discussions, it becomes clear that coloniality is a reality also in the digital society. Universal Internet connectivity does not necessarily equate to truly inclusive connectedness. According to African philosopher Achille Mbembe, we must realize that coloniality is more than academic discourses and representations (Mbembe 2001). It is a systemic problem, materialized in the real world and felt in

\footnotetext{
${ }^{5}$ https://www.kasadaka.com/ (Accessed 1 May 2021)
} 
everyday life by many people. If we want to build a more human-centered, participatory, and democratic digital society - inclusive also for the most vulnerable communities - new ways of collaboration, innovation, and co-creation are needed. In this chapter, we have tried to present some directions on how this could be done.

\section{References}

Baart, A., Bon, A., De Boer, V., Dittoh, F., Tuijp, W. and Akkermans, H. (2019) “Affordable Voice Services to Bridge the Digital Divide - Presenting the Kasadaka Platform" in Escalona, M.J., Mayo, F.D., Majchrzak, T.A., Monfort, V. (eds) Web Information Systems and Technologies, LNBIP Book Series, Vol. 327, pp. 195-220. Berlin, Germany: Springer.

Berners-Lee, T. (2017) Three Challenges for the Web, According to its Inventor. [Online]. Available at: https://webfoundation.org/2017/03/web-turns-28-letter/ (Accessed: 1 May 2021).

Berners-Lee, T. (2019) The Web is under Threat. Join us and Fight for it. [Online] Available at: https://webfoundation.org/2018/03/web-birthday-29/ (Accessed: 1 May 2021).

Dittoh, F., Akkermans, H. De Boer, V. Bon, A. Tuyp, W. and Baart, A. (2021) "Tibansim: Information Access for Low-Resource Environments" in Yang, X.S., Sherratt, S., Dey, N., Joshi, A. (eds) Proceedings of the Sixth International Congress on Information and Communication Technology: ICICT 2021, London, UK, Vol. 1, Singapore: Springer. Available at: https:// w4ra.org/wp-content/uploads/2014/02/ICICT_2021_paper_289.pdf (Accessed: 1 May 2021).

Lee, E.A. (2020) The Coevolution: The Entwined Futures of Humans and Machines. Cambridge MA, USA: MIT Press.

Grewal, D. S. (2008) Network Power: The Social Dynamics of Globalization. New Haven, USA \& London, UK: Yale University Press.

Harris, R., Ramaiyer, N.A.N.K. and Tarawe, J. (2018) "The eBario Story: ICTs for Rural Development" In International Conference on ICT for Rural Development (ICICTRuDev) pp. 63-68, IEEE.

Mignolo, W.D. and Walsh, C.E. (2018) On Decoloniality: Concepts, Analytics, Praxis. Durham, NC, USA: Duke University Press.

Mendoza, B. (2021) "Decolonial Theories in Comparison" in Shih S., Tsai, L. (eds) Indigenous Knowledge in Taiwan and Beyond. Sinophone and Taiwan Studies, Vol .1, pp. 249-271, Singapore: Springer.

Lô, G., de Boer, V., Schlobach, S. and Diallo, G. (2017) "Linking African Traditional Medicine Knowledge". Semantic Web Applications and Tools for Healthcare and Life Sciences (SWAT4LS), Rome Italy. [Online] Available at: https://hal-archives-ouvertes.fr/hal01804941/document (Accessed 1 May 2021).

Mohamed, S., Png, M.T. and Isaac, W. (2020) "Decolonial AI: Decolonial Theory as Sociotechnical Foresight in Artificial Intelligence". Philosophy \& Technology, Vol. 33 No. 4, pp. 659-684.

Mbembe, A. (2001) On the Postcolony. Studies on the History of Society and Culture, Vol. 41, Los Angeles, USA: University of California Press. 
Pini, M.E. (2020) "Digital Inequality in Education in Argentina". In Proceedings of the 12th ACM Conference on Web Science (WebSci '20 Companion), July 6-10, 2020, Southampton, UK, pp. 37-40, New York, NY, USA: ACM. Available at: https://doi.org/10.1145/3394332. 3402827.

Quijano, A. (2016) "Bien Vivir - Between Development and the De/Coloniality of Power". Alternautas (Re) Searching Development: The Abya Yala Chapter 3(1) pp. 10-23. [Online] Available at: http://www.alternautas.net/blog/2016/1/20/bien-vivir-between-development-andthe-decoloniality-of-power1 (Accessed 1 May 2021).

Vos, S., Schaefers, H., Lago, P. and Bon, A. (2020) "Sustainability and Ethics by Design in the Development of Digital Platforms for Low-Resource Environments". [Online]. Amsterdam Sustainability Institute Integrative Project Technical Report. pp. 1-43, Vrije Universiteit Amsterdam. Available at: https://w4ra.org/wp-content/uploads/2021/01/ICT4FoodSec.pdf (Accessed 1 May 2021).

Zuboff, S. (2019) The Age of Surveillance Capitalism: The Fight for a Human Future at the New Frontier of Power. London, UK: Profile Books.

Open Access This chapter is licensed under the terms of the Creative Commons Attribution 4.0 International License (http://creativecommons.org/licenses/by/4.0/), which permits use, sharing, adaptation, distribution and reproduction in any medium or format, as long as you give appropriate credit to the original author(s) and the source, provide a link to the Creative Commons license and indicate if changes were made.

The images or other third party material in this chapter are included in the chapter's Creative Commons license, unless indicated otherwise in a credit line to the material. If material is not included in the chapter's Creative Commons license and your intended use is not permitted by statutory regulation or exceeds the permitted use, you will need to obtain permission directly from the copyright holder. 